\title{
Romancing the Phone: Increasing Executive Response Rates in Strategic Management Research
}

\author{
Padraic Regan \\ Assistant Professor in International Strategic Management \\ School of Business, Trinity College Dublin, Ireland \\ E-mail: pregan@eircom.net
}

Received: May 23, 2012

Accepted: June 5, 2012 Published: July 1, 2012

doi:10.5296/jmr.v4i3.1845

URL: http://dx.doi.org/10.5296/jmr.v4i3.1845

\begin{abstract}
Empirical research requires some form of data collection or evidence in order to test a hypothesis. Conducting research in the area of strategic management invariably necessitates data collection from an organisation's most senior executives but such activity is becoming increasingly difficult. So how can researchers improve their prospects of accessing these most valuable of resources? This paper is based on a particular research study which required responses from executives involved in a specific area of the international services sector. The results show that a combination of techniques had to be deployed in order to attain the targeted sample, including customised 'gentle reminder' phone calls. Moreover, the techniques selected must be tailored to the characteristics of the respondent in question. Management researchers may well benefit in their empirical endeavours by following the recommendations put forward. Limitations and future research recommendations are also outlined.
\end{abstract}

Keywords: Response Rates, Survey Research, Topic Salience, Strategic Management, Social Network Sponsorship 


\section{Introduction}

By combining the esteemed views of Ketchen and colleagues that "there is no doubt that interest in and attention to strategic management research has been increasing dramatically over time" (2008, p. 643) with those of Cycyota and Harrison that "much of the information required to understand organizations must come from the people who lead them: top managers or executives" (2006, p. 133), we arrive at the inevitable conclusion that researchers in strategic management increasingly need access to senior executives (Molina-Azorin, 2012). Unfortunately, this relationship is not one of mutual appreciation as most senior managers can conduct their activities without any recourse to the academic research community. Moreover, in an increasing globalised and competitive environment, potential respondents seem to have less time and inclination to comply with such requests. Hence, a form of 'survey fatigue' appears to be contributing to declining response rates across the behavioural sciences (Baruch, 1999). So what techniques should be deployed in accessing executives, in what order, and for how long?

This paper seeks to address this question by reviewing the literature on enhancing executive survey responses and evaluating their application to a specific empirical strategic management study.

\section{Theoretical Background}

Increasing executive response rates not only makes the sample more representative of the population under investigation but also lowers the likelihood of non-response bias, viz. differences between respondents and non-respondents (Werner, Praxedes and Kim, 2007). Alas, "access to organizations, the people in them, and rich data about them present a significant challenge for management scholars..." (Bono and McNamara, 2011, p. 657).

Of the different research strategies deployed, surveys are "the most commonly used method of data collection in field research” (Hinkin, 1995, p. 967). Survey research can take many modes, including face-to-face ("the most flexible of survey modes"; Dillman and Christian, 2003, p. 5), mail (Dillman, 1991), telephone (Groves, 1990), e-mail (Schaefer and Dillman, 1998) and internet / web-based applications (Cole, Bedeien and Field, 2006; Cook, Heath and Thompson, 2000; Dillman and Tortora, 1998), with each [survey] mode favouring "the construction of questions in ways that differ from those favoured by each of the other modes" (Dillman and Christian, 2003, p. 20).

Whilst numerous studies have examined techniques for enhancing response rates to mailed surveys (e,g. Baruch, 1999; Dillman, 1991), perhaps the most significant contribution that concentrates specifically on executives is the meta-analysis study reported by Cycyota and Harrison (2006). This study sought to identify anything unique to surveying executives and tested four response enhancement techniques, viz. topic salience, prior consent screening of samples, sponsorship, and the inclusion of an incentive, advance notice, follow-up, and personalisation of survey and cover letter. The results of the review of 231 studies from 1992 to 2003 involving 256,215 recipients found only one contributor to response rate, topic salience, i.e. basing the survey on a current or 'hot' issue for the executives in question. 


\section{Testing of Recommended Techniques}

The research question of the study that this paper is based on included the type of strategic decision-making processes used by the organisations in the sector, i.e. European airports. Hence, direct evidence from executives in the industry was required.

Testing of the aforementioned enhancement techniques started with the content element, i.e. topic salience was designed in to the questionnaire introduction. The first page of the survey contained a short, visually- and topically-impactful statement relating to the following major challenge facing the target industry: "Projections for European air passenger numbers indicate growth of 5\% - 6\% per annum - a doubling by 2020”. This independent event was aimed at capturing the interest of executives and creating a cooperative "context-induced mood” (Podsakoff, MacKenzie, Lee and Podsakoff, 2003, p. 884). A second content element related to language; even though the target population was spread across 45 countries speaking over 20 languages, English is the adopted language of the European aviation sector, e.g. air traffic control services, and hence translation issues did not arise (Lyness and Kropf, 2007; Presser et al, 2004).

Next, the process elements were deployed, starting with social network sponsorship which was addressed here by approaching the industry's trade association (which represents the overwhelming majority of organisations in the industry). By focusing on these existing social exchange relationships, researchers can obtain increased attention to their surveys rather than relying on unsolicited mail from unknown parties (Cycyota and Harrison, 2006). The questionnaire was distributed as an attachment to an email from the trade association (one week after an advanced notification email) with a covering note describing the significance of the research and requesting cooperation. One month later, a follow-up email was sent, again with the questionnaire attached. One month after that, the researcher used personal contacts in the industry to promote the research at various committee meetings of the trade association. As the sample was still not complete, the final stage of the data collection process took the form of direct personalised telephone contact. Care was taken not to harass or pressurise potential respondents so no further efforts were made to elicit responses (Cycyota and Harrison, 2006).

\section{Results}

A total of 98 individual executives from individual airports in 29 European countries returned completed questionnaires, a response rate of $24 \%$ on the basis of the target population. As the entire data collection process took place over an eight-month period and a time span of at least a month was allowed to pass between each of the response enhancement processes, a rough guide as to the effectiveness of the four separate process phases can be attempted. Attempting to distinguish between the advanced notification email, the topic salience incorporated into the questionnaire and the email from the trade association containing the questionnaire as an attachment, was considered unreasonable and hence these are all included in phase 1 which generated $45 \%$ of the final sample. A further $12 \%$ of responses can be reasonably attributed to the follow-up email issued by the trade association. The use of personal contacts trumpeting the importance of the research at various trade association 
committee meetings appears to have stimulated another 15\%. Finally, personalised telephone contact in the form of a 'gentle reminder' seems to be responsible for completing the sample, the final $26 \%$ (see Figure 1). It should be pointed out that these approximations are not purporting to represent direct 'cause and effect' relationships but nevertheless sufficient time was allowed to conclude that responses had completely dried up before the next phase was embarked upon.

\section{Conclusions and Recommendations}

Although the effectiveness of topic salience as a method for increasing executive survey responses was not explicitly measured in this study, a potential proxy for same may well be indicated by the $85 \%$ of respondents who requested a copy of the research findings (accepting that the trade association's 'validation' of the importance of the research may well have contributed to this figure also). The relatively small result (although each response was hugely appreciated) generated by the follow-up email might suggest that the usefulness of either network sponsorship or email as a communication method or both had been exhausted at that point. The third phase also elicited a relatively small number of additional responses which may indicate that third parties cannot be expected to have the same enthusiasm in promoting the research as the researcher him/herself. This is reinforced by perhaps the most important finding of this study: that personalised direct contact by phone (on the basis of a polite, gentle reminder) can have a significant impact on increasing executive survey responses in strategic management research.

Although international in design, this paper was based on a single, cross-sectional questionnaire in a single industry on a single Continent; hence its generalisability is limited. Moreover, the type and order of the techniques used may well have yielded a larger response rate in a different sequence. Future researchers in this area might fruitfully expand the industry, geography, techniques, order and timeframes.

\section{References}

Baruch, Y. (1999). Response Rate in Academic Studies - A Comparative Analysis. Human Relations, 52(4), 421-438. http://dx.doi.org/10.1023/A:1016905407491

Bono, J.E., \& McNamara, G. (2011). From the Editors: Publishing in AMJ - Part 2: Research Design. Academy of Management Journal, 54(4), 657-660.

Cole, M. S., Bedeian, A. G., \& Field, H.S. (2006). The Measurement Equivalence of Web-Based and Paper-and-Pencil Measures of Transformational Leadership: A Multinational Test. Organizational Research Methods, 9(3), 339-368. http://dx.doi.org/10.1177/1094428106287434

Cook, C., Heath, F., \& Thompson, R.L. (2000). A Meta-Analysis of Response Rates in Webor Internet-Based Surveys. Educational and Psychological Measurement, 60(6), 821-836. http://dx.doi.org/10.1177/00131640021970934 
Cycyota, C. S., \& Harrison, D. A. (2006). What (not) to expect when surveying Executives: A Meta-analysis of Top Manager Response Rates and Techniques over time. Organizational Research Methods, 9(2), 133-160. http://dx.doi.org/10.1177/1094428105280770

Dillman, D. A. (1991). The design and administration of mail surveys. Annual Review of Sociology 17, 225-250. http://dx.doi.org/10.1146/annurev.so.17.080191.001301

Dillman, D. A., \& Christian, L. M. (2003). Survey Mode as a Source of Instability in Responses across Surveys. Paper available at: http://survey.sesrc.wsu.edu/dillman/papers.

Dillman, D., \& Tortora, R. (1998). Principles for constructing respondent-friendly Web surveys and their influence on response, paper presented at American Statistical Association Meeting, Dallas, TX. Paper available at: ttp://survey.sesrc.wsu.edu/dillman/papers.htm.

Groves, R. M. (1990). Theories and Methods of Telephone Surveys. Annual Review of Sociology, 16, 221-240. http://dx.doi.org/10.1146/annurev.so.16.080190.001253

Hinkin, T. R. (1995). A Review of Scale Development Practices in the Study of $\begin{array}{llll}\text { Organizations. Journal of } & \text { 967-988. }\end{array}$ http://dx.doi.org/10.1177/014920639502100509

Ketchen, Jr. D. J., Boyd, B. K., \& Bergh, D. D. (2008). Research Methodology in Strategic Management: Past Accomplishments and Future Challenges. Organizational Research Methods, 11(4), 643-658. http://dx.doi.org/10.1177/1094428108319843

Lyness, K. S., \& Kropf, M. B. (2007). Cross-National Differences in Mail Survey Response Rates, Cultural Values and Potential Nonresponse Bias: A Multilevel Examination of Cross-National Differences in Mail Survey Response Rates. Organizational Research Methods, 10(2), 210-224. http://dx.doi.org/10.1177/1094428106291060

Molina-Azorin, J. F. (2012). Mixed Methods Research in Strategic Management: Impact and Applications. Organizational Research Methods, 15(1), 33-56. http://dx.doi.org/10.1177/1094428110393023

Podsakoff, P.M., MacKenzie, S.B., Lee, J.Y., \& Podsakoff, N.P. (2003). Common Method Biases in Behavioral Research: A Critical Review of the Literature and Recommended Remedies. Journal of Applied Psychology, 88(5), 879-903. http://dx.doi.org/10.1037/0021-9010.88.5.879

Presser, S., Couper, M.P., Lessler, J.T., Martin, E., Martin, J., Rothgeb, J.M., \& Singer, E. (2004). Methods for Testing and Evaluating Survey Questions. Public Opinion Quarterly, 68(1), 109-130. http://dx.doi.org/10.1093/poq/nfh008

Schaefer, D. R., \& Dillman, D.A. (1998). Development of a Standard E-mail Methodology: Results of an Experiment. Public Opinion Quarterly, 62(3), 378-397. http://dx.doi.org/10.1086/297851 


\section{Macrothink}

Werner, S., Praxedes, M., \& Kim, H.G. (2007). The Reporting of Nonresponse Analyses in Survey Research. Organizational Research Methods, 10(2), 287-295. http://dx.doi.org/10.1177/1094428106292892

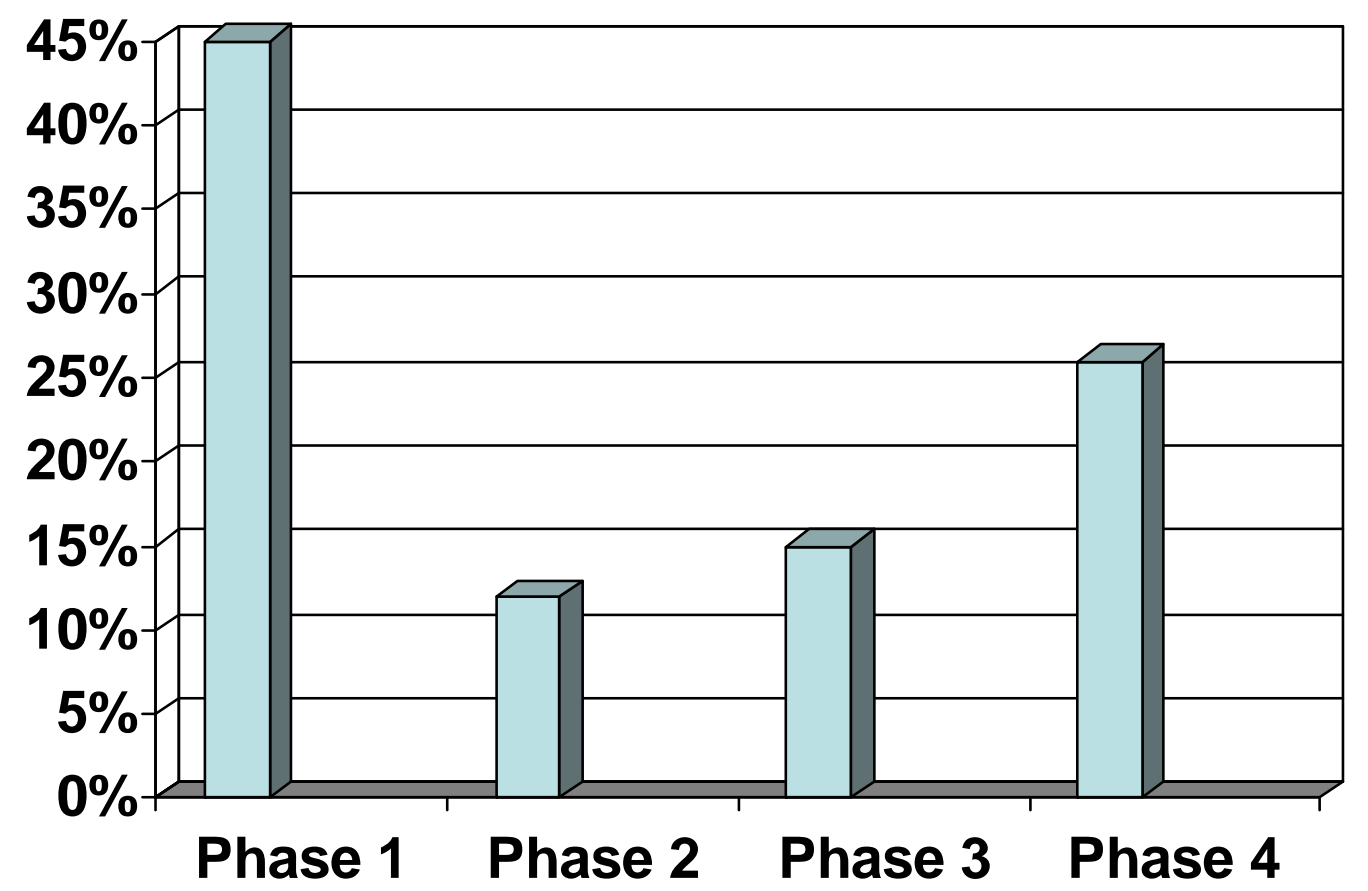

Figure 1. Relative Effectiveness of Techniques 